\title{
Suicide prevention gatekeeper training in the Netherlands improves gatekeepers' knowledge of suicide prevention and their confidence to discuss suicidality, an observational study
}

\author{
Sanne Terpstra ${ }^{1 *}$, Aartjan Beekman ${ }^{1,2}$, Jens Abbing 3 , Sabine Jaken ${ }^{4}$, Martin Steendam ${ }^{5}$ and Renske Gilissen ${ }^{4}$
}

\begin{abstract}
Background: The gatekeeper training is designed to help identify suicidal individuals, respond to suicidal ideation and refer to help. The internationally widely used training shows promising results. This is the first study presenting its effectiveness in the Netherlands and the first study investigating the effect in different employment sectors.

Methods: In an observational study, 113 Suicide Prevention - the Dutch suicide prevention expertise centre and lifeline - trained 526 professionals as gatekeepers. Changes in gatekeepers' identifying and referral behaviour, knowledge of suicide prevention and skills-confidence were studied, using a pre-post (6 weeks after training) self-report questionnaire. Outcomes were analyzed with General Linear Model (GLM) repeated measures with four employment sectors (healthcare-, educational-, socioeconomic and other sectors) as a between-subjects factor.

Results: Pre-post self-reports of 174 respondents showed no change in the identification of suicidal people, referrals to the general practitioner (GP) or lifeline 113, but significant improvement in professionals' knowledge and confidence $(p<.001)$. Results did not differ between employment sectors.

Conclusions: The gatekeeper training significantly increases suicide prevention knowledge and skills confidence in abilities to address suicidality. Healthcare, education, socioeconomic and other professionals (e.g. security, justice, transport, church workers) benefit similarly from the training. Increasing the number of gatekeeper training programs in all sectors is recommended.
\end{abstract}

Keywords: Gatekeeper training, Suicide prevention, Observational study, Employment sectors

\section{Background}

In the Netherlands 1893 people died by suicide in 2016 in a population of almost 17 million. In 2007 the number of suicidal deaths was 1353 [1]. After correcting for population growth, the suicide rate increased by $34 \%$ (2007:8.3 per 100,000; 2016:11.1 per 100,000). Given the increase in suicidal deaths, several actions have been

\footnotetext{
* Correspondence: Sanne.Terpstra@ggzingeest.nl

'Department of Research \& Innovation, GGz InGeest, Amsterdam, The Netherlands

Full list of author information is available at the end of the article
}

undertaken in recent years to organize suicide prevention activities in mental healthcare settings and beyond. In 2012, a Multidisciplinary guideline to diagnose and treat suicidal behaviour in Dutch mental healthcare [2] was published. The number of suicides among clients of mental healthcare settings, as reported by the Dutch Ministry of Health, Welfare and Sport shows that about $50 \%$ of Dutch citizens who died by suicide were or had been in treatment [3], implying that $50 \%$ of Dutch suicides were unknown in mental healthcare settings. This shows the importance of identifying and assisting people

(c) The Author(s). 2018 Open Access This article is distributed under the terms of the Creative Commons Attribution 4.0 International License (http://creativecommons.org/licenses/by/4.0/), which permits unrestricted use, distribution, and reproduction in any medium, provided you give appropriate credit to the original author(s) and the source, provide a link to the Creative Commons license, and indicate if changes were made. The Creative Commons Public Domain Dedication waiver (http://creativecommons.org/publicdomain/zero/1.0/) applies to the data made available in this article, unless otherwise stated. 
with suicidal ideation in healthcare but also within community settings such as schools, volunteer organizations or social services.

The Dutch suicide prevention expertise organization, 113 Suicide Prevention, provides a telephonic and digital 'lifeline' for anonymous help. In 2013 the organization launched a National Agenda on suicide prevention with the support of the Dutch Ministry of Health. Effectuation and evaluation of the National Agenda was carried out by 113 in close collaboration with social community organizations and the national railway company (ProRail). The common goal was to contribute to a decrease in Dutch suicide rates by initiating and encouraging the realization of suicide prevention policies and other preventive activities. As there is a general consensus that the pathways to suicidality consist of a multiple factors [4, 5], the Agenda was directed at five domains: (mental) healthcare, (social) media, education, the socioeconomic and transport sector. One of the important actions undertaken was disseminating gatekeeper trainings in community settings such as schools, GP offices and social services.

Acknowledgment for the National Agenda initiative comes from the World Health Organization (WHO), recommending multiple level interventions in community environments in its report Preventing Suicide: a Global Imperative [6]. Some multi-level interventions on suicide prevention have been extensively studied and show promising results [7-15]. A desirable effect of gatekeeper trainings as part of such a program can be found in several studies [11, 16-19], showing a progressive reduction in suicide rates in the intervention communities. The effects of the training itself though, are difficult to discern since they were part of these multilayered intervention programs. Nevertheless, besides multi-level actions, the gatekeeper training as a standalone strategy seems to bring about positive results as well [20-22], apart from resident assistants in a randomized controlled trial who showed no effects on intervention behaviour [23] after a 1-h gatekeeper training.

In most studies, knowledge improvement is a convincing outcome of the gatekeeper training [16, 24-29] as well as improved self-efficacy $[25,28,30,31]$ and confidence to act when in contact with a suicidal person $[16$, 24, 27, 32]. Furthermore, gatekeeper training seems beneficial in referring youth to appropriate services, especially within school-based settings $[33,34]$. The improved self-efficacy found in Chauliacs controlled study resulted in significantly more referrals to psychologists [24]. On the other hand, four uncontrolled studies found that participants with higher pre-training intentions to help, were more likely to actually reach out to a person in a suicidal crisis and showed a decline in referral behaviour [26]. Heightened awareness of suicidal signs is another goal targeted by most gatekeeper trainings.
Tsai's randomized controlled trial showed that nurses' recognition of signs significantly increased [35]. Also for clergy, after attending a gatekeeper training their knowledge, among other factors, improved and contributed to better prediction of high risk individuals [36].

Despite differences in training methodology, duration, content and target group, the general goal of gatekeeper training is to learn how to respond to a suicidal person by starting a "caring dialogue" [37] and "open the gates" $[26,38]$ to further help when needed, for example by referring to a mental healthcare professional [39]. Still, while gatekeeper training is a frequently used and widely assessed intervention, various studies suggest gatekeeper training programs for preventing suicide need more thorough study to determine their ultimate effectiveness $[15,16,39,40]$.

This is the first Dutch study on the effectiveness of gatekeeper training in the Netherlands. Firstly, to explore the effect of gatekeeper training content on participants in the Netherlands, but also to study to what extent sectors differ in the reception of suicide prevention training and thus gain insight into the potential of the employment sectors to suicide prevention.

\section{Gatekeeper training in the Netherlands}

The gatekeeper training frequently referred to is based on the method of Question, Persuade, Refer (QPR) and was originally set up as a mental health intervention for those in a suicidal emergency [37]. Gatekeeper training is usually given to either designated professionals (such as counselors and GPs) specialized in helping people in crisis or to community members with facilitating jobs, not trained in dealing with a potential mental healthcare crisis (such as educational staff) [38]. These community workers can play a crucial role in responding to suicidality because they are likely to meet a diversity of people, including people who do not seek mental help themselves. In particular, employees in unemployment benefit agencies and social services have a higher probability of interacting with suicidal clients at their workplace [41].

In 2008 the gatekeeper training was tailored for application in the Netherlands [42]. Since then, a variety of professionals have been trained, such as teachers, clergymen, police-officers, social workers, general practitioners and bailiffs. In 2014 the gatekeeper training program was handed over to 113 Suicide Prevention for further dissemination.

The Dutch gatekeeper training program is designed as skills training with a duration of four hours and is based on the QPR principles [43]. It consists of four main parts: (i) introduction, (ii) theoretical background, (iii) role-plays and (iv) referral pathways. In the introduction, the topic of suicide is explored and attendees share their experiences. The theoretical background focuses on the 
epidemiology of suicide, risk factors and possible causes, and stresses the global consensus of experts that talking about suicidal ideation can help to prevent suicide. After this, role-plays are performed by trainees and are repeated three times in order to deepen the skills and consolidate the trainees' confidence. Finally, there is a plenary discussion on the best routes for referral and further help.

Each training is administered by two trainers. In the time period corresponding with this study (January 2015 until July 2016) 113 Suicide Prevention worked with approximately 20 gatekeeper trainers. Almost half of them had conducted this training several times before. Trainers were employed by mental healthcare institutions, or were selected at the start of 2015 after an application procedure. They received a two-day train-thetrainer program, identical to that of the experienced trainers. Some trainers worked in mental or public healthcare, some were trainers by profession but had no experience in healthcare or with suicide prevention. The trainers trained in pairs, and pairs varied per training.

So far, in the Netherlands no studies have been conducted on the effects of gatekeeper training on suicide prevention. This study aims to fill that gap. Not only will it (1) determine the short-term effectiveness of the gatekeeper training program on individual participants in terms of a) identifying and referral behaviour; b) knowledge of suicide prevention; and c) confidence in the ability to have a dialogue about suicidality with a person with suicidal ideation. It also aims to (2) ascertain whether the training has different outcomes for different employment sectors. To our knowledge, comparison of multiple sectors in one study has not been conducted previously. Healthcare professionals might benefit less from the gatekeeper training than staff from the educational sector, the socioeconomic sector or other employment sectors, due to their prior education and thus higher pre-test abilities. As a consequence, these professionals may already be more familiar and thus more at ease discussing difficult health issues.

\section{Method}

\section{Participants and procedure}

One hundred thirteen Suicide Prevention contacted organizations within different employment sectors to offer the gatekeeper training. From these organizations, employees volunteered to participate in the training. The training program of 113 Suicide Prevention accepted a maximum of 16 and a minimum of 10 participants per training. From January 2015 until July 2016113 Suicide Prevention trainers carried out 42 gatekeeper trainings $(2015: 23 ; 2016: 19)$ and trained 526 individuals (2015: $n=305 ; 2016: n=221$ ).
On entering the training facilities, participants were asked to fill in a questionnaire (t0), prior to the start of the training. Participants who arrived on time $(N=502)$ filled in this baseline questionnaire ( $\mathrm{t} 0$ ). Approximately 6 weeks after baseline, 113 Suicide Prevention sent the same questionnaire by email for follow-up ( $t 1)$. When no response was received, 113 sent a digital reminder. Of all baseline responders, 174 filled in the onlinesurvey post-training (response rate 34.7\%). Responders did not differ from nonresponders on their pretraining scores: $t_{\text {identifying }}(497)=-1.28, p=.20 ; t_{\text {refer- }}$ $\operatorname{ralGP}(498)=-1.45, p=.15 ; t_{\text {referral113 }}(208.379)=1.22$, $p=.23 ; t_{\text {knowledge }}(470)=0.29, p=.77 ; t_{\text {confidence }}(481)$ $=-0.65, p=.52$.

Of all responding participants, 49 worked in the educational sector, 70 in the healthcare sector, 32 were employed in the socioeconomic sector and 23 in other sectors like security and justice, transport or churches and mosques. When comparing responders and nonresponders per sector, an equal proportion worked in the education sector ( $28.2 \%$ vs $24.4 \%$ ), healthcare sector ( 40 . $2 \%$ vs $40.9 \%)$, socioeconomic sector ( $18.4 \%$ vs $22.3 \%)$ and other employment sectors (13.2\% vs $12.5 \%)$.

\section{Measures}

Prior to the training, participants were asked to fill in the date of training, name, email address and profession or professional organization. Furthermore, the questionnaires pre- and post-training consisted of a subset of ten questions (Additional file 1), derived from previously validated questionnaires. The subset was partially adopted from an original gatekeeper training survey [29], designed to study the effect of a QPR training amongst secondary school staff using a group-based randomized trial. Added to the items on knowledge were three survey questions assessing confidence on talking about suicide by healthcare staff, used in a cluster randomized controlled trial [44] and an empirical assessment and treatment study [45]. The impact of the gatekeeper training was analyzed for identifying people at risk of suicide, referral to GP, referral to 113 Suicide Prevention, knowledge and confidence.

\section{Analyses}

Because each participant had been measured on two occasions (before and approximately six weeks after the gatekeeper training) on the same questionnaire, a GLM Repeated Measures was conducted to reveal if the training improved their identifying (question 1) and referral behaviour (question 2 and 3), their knowledge on suicide prevention (sumscore of questions 4-7) and their confidence in their abilities (sumscore of questions 8-10; research question 1). The last item in the confidence questions (I hesitate to ask someone if he/she is suicidal) 
was recoded so that a high score represents less hesitation to ask clients about suicidality.

To compare the training effects for participants from different sectors (research question 2), employment sector was entered as a between-subjects factor in the repeated measures analysis. Participants were categorized into four different employment sectors. The following sectors were distinguished: (1) education (student career counselors, teachers, student psychologists, school social workers); (2) healthcare (mental healthcare professionals, GPs, social workers, social community teams, first aid workers); (3) socioeconomic sector (bailiffs, vocational experts, bank employees, insurance doctors, debt counselors and administrators); (4) other (security, justice, transport, church workers, imams etc). All analyses were performed using SPSS 24.0.

\section{Results}

Five hundred two participants filled in the questionnaire at pre-training and 174 at post-training (Response rate $35 \%)$. Response rates between different sectors varied between 30 and 38\% (Table 1).

Table 2 provides an overview of the pre- and posttraining mean scores for each item of the questionnaire. None of the three items about identifying and referral behaviour differed significantly after training compared to before. Thus, the number of suicidal people that were spoken to by participants, the number of people that were referred to a GP or to 113 Suicide Prevention by participants, did not change after training. However, the training had highly significant positive effects $(p<.001)$ on the items of knowledge and confidence, demonstrating that after being trained, participants had more knowledge about suicide and felt more equipped to talk to suicidal people and to refer them to appropriate sources for help. The standardized effect sizes (Cohen's d) were - 0.03 (95\% CI -0.32 to 0.26$)$ for Identifying, $-0.14(-0.36$ to 0.12$)$ for Referral to GP, 0.23 ( -0.13 to 0.43 ) for Referral to 113, 1.17 (0.83 to 1.59) for Knowledge, and 0.74 (0.43 to 1.09$)$ for Confidence.

Mean scores on pre- and post-training items per employment sector are presented in Table 3 . The repeated measures ANOVA with employment sector as a between

Table 1 Characteristics of the study population

\begin{tabular}{llll}
\hline Sector & N & N & Response rate (\%) \\
& Pre-training & Post-training & \\
\hline Education & 129 & 49 & 38 \\
Healthcare & 204 & 70 & 34 \\
Socioeconomic & 105 & 32 & 30 \\
Other & 64 & 23 & 36 \\
Total & 502 & 174 & 35 \\
\hline
\end{tabular}

Table 2 Comparison between pre-and post-training results per item

\begin{tabular}{llll}
\hline Item & $\begin{array}{l}\text { Pre-training (T0) } \\
\text { Mean(SD) }\end{array}$ & $\begin{array}{l}\text { Post-training (T1) } \\
\text { Mean(SD) }\end{array}$ & $F$ \\
\hline 1. Identifying & $1.23(1.86)$ & $1.17(1.84)$ & 0.36 \\
2. Referral to GP & $0.88(1.65)$ & $0.67(1.38)$ & 3.89 \\
3. Referral to 113 & $0.27(1.29)$ & $0.68(2.23)$ & 1.27 \\
4. Knowledge & $11.49(2.69)$ & $14.30(2.11)$ & $187.83^{* * *}$ \\
5. Confidence & $9.54(2.25)$ & $11.08(1.93)$ & $84.44^{* * *}$ \\
\hline$* * * 0.001$ & & &
\end{tabular}

subjects variable showed no interaction effect between employment sector and item scores pre- and post-training $\left(\mathrm{F}_{\text {identifying }}(3,150)=0.39, p>.05 ; \mathrm{F}_{\text {referralGP }}(3,150)=0.75\right.$, $p>.05 ; \mathrm{F}_{\text {referral113 }}(3,150)=1.11, p>.05 ; \mathrm{F}_{\text {knowledge }}(3,150)$ $\left.=1.02, p>.05 ; \mathrm{F}_{\text {confidence }}(3,150)=1.01, p>.05\right)$.

To examine whether the employment sectors started off the same at baseline, post hoc tests using the Bonferroni correction [46] revealed that participants working in the healthcare sector reported a significantly higher number of people with suicidal thoughts they had identified preand post-training, compared to the other employment sectors $(p<.001)$, and rated themselves as having more baseline knowledge and confidence compared to participants working in the socioeconomic sector $(p=.001)$. Therefore, we can conclude that while participants working in the mental healthcare sector often rate themselves higher, the effect of a gatekeeper training program does not depend on the sector that participants work in and elicits a statistically significant improvement in participants' knowledge and in their confidence in abilities to address suicide.

\section{Discussion}

This study was conducted to evaluate the effect of a suicide prevention gatekeeper training in the Netherlands among education professionals (student career counselors, teachers, student psychologists, school social workers), designated healthcare professionals (mental healthcare professionals, GPs, social community teams, first aid workers), employees in the socioeconomic sector (bailiffs, vocational experts, bank employees, insurance doctors, debt counselors and administrators) and other professionals (security, justice, transport, church workers, imams).

The results confirm that the training was effective in all employment sectors in improving participants' knowledge on suicide and addressing suicidality, and in their self-confidence to conduct a dialogue on suicide and suicidal thoughts. Six weeks after the gatekeeper training, all participants benefitted significantly from the training on these topics. These outcomes are consistent with other studies on gatekeeper 
Table 3 Pre- and post-training mean scores per employment sector

\begin{tabular}{|c|c|c|c|c|c|c|c|c|}
\hline \multirow[b]{3}{*}{ Item } & \multicolumn{8}{|l|}{ Sector } \\
\hline & \multicolumn{2}{|l|}{ Educa tion } & \multicolumn{2}{|l|}{ Health care } & \multicolumn{2}{|l|}{ Socio- economic } & \multicolumn{2}{|l|}{ Other } \\
\hline & T0 Mean (SD) & T1 Mean (SD) & T0 Mean (SD) & T1 Mean (SD) & T0 Mean (SD) & T1 Mean (SD) & T0 Mean (SD) & T1 Mean (SD) \\
\hline 1. Identifying & $0.84(1.11)$ & $0.91(1.21)$ & $2.10(2.46)$ & $1.97(2.30)$ & $0.38(0.62)$ & $0.45(1.35)$ & $0.58(0.77)$ & $0.21(0.42)$ \\
\hline 2. Referral GP & $1.30(2.40)$ & $0.95(1.40)$ & $0.78(1.13)$ & 0.79 (1.68) & $0.62(1.43)$ & $0.21(0.68)$ & $0.68(1.34)$ & $0.32(0.75)$ \\
\hline 3. Referral 113 & $0.07(0.26)$ & $0.72(1.05)$ & $0.35(1.48)$ & $0.92(3.27)$ & $0.07(0.37)$ & $0.38(1.05)$ & $0.74(2.42)$ & $0.21(0.71)$ \\
\hline 4. Knowledge & $11.65(2.43)$ & $14.44(1.88)$ & $12.19(2.32)$ & $14.87(1.72)$ & $10.00(2.79)$ & $13.41(2.24)$ & $11.11(3.38)$ & $13.42(2.85)$ \\
\hline 5. Confidence & $9.30(2.36)$ & $11.14(1.81)$ & $10.33(1.95)$ & $11.56(1.93)$ & 8.59 (2.03) & $10.17(1.85)$ & $8.89(2.51)$ & $10.74(1.91)$ \\
\hline
\end{tabular}

training effects, showing primarily increased knowledge and self-confidence [16, 24-32].

With regard to our second research aim - the results from the different sectors of employment - we hypothesized that healthcare staff might be more equipped with knowledge and confidence before attending the training and consequently might have fewer benefits from the training. Indeed, participants working in the healthcare sector rate themselves as having more knowledge and confidence at baseline, compared to participants working in the socioeconomic sector. Also they score higher on identifying suicidality than participants from other sectors at baseline. Surprisingly, at follow-up all participants in all sectors self-report comparable positive results on knowledge and confidence, regardless whether they were educated in healthcare or not. In other words, professionals from various backgrounds all benefited similarly from the gatekeeper training.

Unexpectedly, no effect was found on the number of referrals to either the general practitioner or the lifeline of 113. This outcome is rather disappointing as the gatekeeper training was designed with the goal to address people with suicidal ideation and refer them to appropriate help resources. By training community gatekeepers we expected more suicidal people to be guided towards a help provider in their close vicinity, preferably their general practitioner. In addition, we estimated that 113 would become better known as a source for help by offering the training program, resulting in an increase in referrals to its services.

One way to interpret the significantly positive effect on knowledge and confidence on the one hand and the lack of effect on identifying and referral on the other, is the design of the questionnaire. It combines heterogeneous items, so the outcomes are likely to vary. It can be assumed that participants of the gatekeeper training were continuously exposed to knowledge about suicide and were encouraged to deal with the topic. Taking this into account, it is not surprising that knowledge and confidence items achieve a proximal effect, which we see in our results. On the other hand, questions about identification and referral relate to more distal effects and therefore are less likely to be found in the short period of time (about 6 weeks) between baseline and follow-up.

Another reason that no effect in referral behaviour was found can be due to the greatly diminished group of respondents at follow-up compared to baseline. The group that completed both questionnaires $(N=174)$ did not differ in baseline results from the group that completed only the baseline questionnaire $(N=328)$. In addition, all responders and nonresponders were evenly divided between included sectors: education sector (28. $2 \%$ vs $24.4 \%$ ), healthcare sector ( 40.2 vs 40.9 ), socioeconomic sector (18.4 vs 22.3) and other employment sectors (13.2 vs 12.5). This means that there was no differential non-response and we can rule out any disproportionate difference between responses per sectors.

Yet, the response rate of $35 \%$ at the digital follow-up survey (t1) is a manifest limitation of this study. The low percentage might be ascribed to the different ways we presented the T0 and T1 forms. T0 was handed out at the entrance to the training facilities, where all participants were asked to fill in the questionnaire right at the start of the training program. The $\mathrm{T} 1$ form was sent to the trainees by email. Even when sent a digital reminder to fill in the follow-up, the response numbers remained low.

A contextual explanation for the lack of effect found in referrals, could be that the gatekeepers did not have proper access to 113, a GP nearby or other help resources. It is plausible that good access to (formal or informal) help will raise the rate of referrals by gatekeepers [29]. Another possibility is that gatekeepers still felt uncomfortable about speaking extensively about suicidality, so their self-reported confidence did not lead to actual behavioural change.

At the same time, most professionals do not often meet a suicidal client; increased post-training effects on this item perhaps were less likely to occur as the time between the training and the second questionnaire was relatively short. This can also explain why no effect in identifying suicidal people was found.

The low response rate may also have influenced outcomes regarding knowledge and confidence. Although 
comparable international studies found similarly low response-rates in follow-up surveys $[47,48]$, we opted to apply Cohen's d to measure the strength of our significantly positive findings. The effect sizes we found, subsequently demonstrate that the power of the effects on enhanced knowledge and confidence are strong: 1.17 (0. 83 to 1.59) for Knowledge, and 0.74 (0.43 to 1.09) for Confidence. Another factor that may had influence on the positive outcomes on knowledge and confidence, is the method of gathering data. This was conducted with a self-report questionnaire and possibly led to socially desirable answers. Still, the choice for self-reporting is a common practice in research on trainings and appropriate in a explorative observational study.

However, the absence of a control group, the second limitation of this study, might also have caused a responders' bias. And although our research design (non-comparative observational analysis) is not uncommon for measuring effect of an intervention in time [49], the internal validity of our effects is relatively low. Most participants voluntarily participated in our training sessions, which possibly caused a selection bias of "natural helpers" [29, 50]. Nevertheless, the effect of the gatekeeper training convincingly improves the knowledge and self-confidence of all attending professionals, accordingly we conclude the external validity of the study remains high.

When looking at the effectiveness and review studies, randomized controlled trials are exceptional [21, 23, 29, $35,51,52]$ in the research on the effect of gatekeeper trainings. Therefore, a comprehensive follow-up study according to the golden standard of randomization would be appropriate.

The few sociodemographic information that was gathered with the questionnaire holds another risk of bias and must therefore be mentioned as a limitation. At this point it is uncertain whether, for example, age, race, or gender affected the outcomes in one way or another. Notwithstanding that all sectors show the same positive outcomes on knowledge and confidence, there is the possibility that the sociodemographic distribution of the responders group was not equal to the nonresponders group.

Finally, our study is not an experimental design, therefore we have to take into account that some external factors may have influenced our results and biased our positive outcomes. In our opinion though, the short time span between baseline and follow-up makes it highly unlikely that such a determining event occurred, so the validity of our statistically positive outcomes remains.

\section{Conclusions}

Given the limitations, our findings show that the gatekeeper training is effective in improving knowledge and skills-confidence for a wide range of professions and thus positively supports gatekeepers' willingness to address suicidality. Moreover, dissemination of the training program could contribute to reducing the taboo on addressing suicide and suicidal thoughts in the immediate vicinity of trainees and even encourage prevention policy within institutions where staff is trained [24, 53]. Based on these considerations and the results of our study, we conclude that increasing the number of gatekeeper training programs in all sectors is recommended.

\section{Additional file}

Additional file 1: Questionnaire Gatekeeper training. Data identifies people at risk of suicide, referral to GP, referral to 113 Suicide Prevention, knowledge and confidence. Personal data of participants and ordinal data on a 5 point scale. (DOCX $15 \mathrm{~kb}$ )

\section{Abbreviations}

CBS/StatLine: Centraal Bureau voor de Statistiek, Statistics Netherlands; GLM: General linear model; GP: General practitioner; IGZ: Inspectie Gezondheidszorg en Jeugd, Dutch Health Care Inspectorate; QPR: Question, persuade, refer

\section{Acknowledgements \\ We thank all participants for participating in this study. Also we thank all the 113 trainers for handing out and collecting the questionnaires from the participants. We thank Michel Plaisier for his help in entering the questionnaires.}

\section{Availability of data and materials}

The training material and dataset of the current study is owned by 113 Suicide Prevention and is available via the corresponding author after reasonable request to 113 Suicide Prevention.

\section{Authors' contributions}

ST drafted the manuscript. $A B, J A, S J, M S$ and RG made critical revisions to the manuscript. RG designed the study and performed the analyses. JA and $A B$ contributed to the data analyses. All authors read and approved the final manuscript.

\section{Ethics approval and consent to participate}

According to the guidelines of the Central Committee on Human Research (CCMO: http://www.ccmo.nl/nl/help-mij-op-weg), no approval of the Medical Ethical Committee is needed for studies with human subjects that are not medical and with participants who are not required to follow rules of behaviour. Data of respondents were anonymized prior to analysis. Consent of participants was given by filling in the questionnaire at T0. Participants were allowed to terminate study participation at any time without giving a reason.

\section{Competing interests}

The authors declare that they have no competing interests.

\section{Publisher's Note}

Springer Nature remains neutral with regard to jurisdictional claims in published maps and institutional affiliations.

\section{Author details}

'Department of Research \& Innovation, GGz InGeest, Amsterdam, The Netherlands. ${ }^{2}$ Department of Psychiatry, VU University Medical Centre, Amsterdam, The Netherlands. ${ }^{3}$ Department of Public and Occupational Health, VU University Medical Centre, Amsterdam, The Netherlands. ${ }^{4} 113$ Suicide Prevention, Amsterdam, The Netherlands. ${ }^{5}$ Department of Psychology, GGz Friesland, Leeuwarden, The Netherlands. 
Received: 4 January 2018 Accepted: 26 April 2018

Published online: 18 May 2018

\section{References}

1. CBS/Statline. Zelfdoding 2007-2016. http://statline.cbs.nl/Statweb/ publication/?DM=SLNL\&PA=7052_95\&D1=88\&D2=0\&D3=0\&D4=57,I\&HDR= G1,G2,G3\&STB=T\&WW=T. Accessed 8 Nov 2016

2. Van Hemert AM, Kerkhof AJFM, De Keijser J, Verweij B, Van Boven C, Hummelen JW, et al. Multidisciplinaire richtlijn diagnostiek en behandeling van suïcidaal gedrag. Utrecht: De Tijdstroom; 2012

3. Rijksoverheid. Kamerbrief over de landelijke agenda suïcidepreventie en Jaarrapportage vermindering suïcidaliteit 2013. https://www.rijksoverheid.nl/ documenten/kamerstukken/2014/01/20/kamerbrief-over-de-landelijkeagenda-suicidepreventie-en-jaarrapportage-vermindering-suicidaliteit-2013. Accessed 12 May 2018.

4. Mann JJ, Apter A, Bertolote J, Beautrais A, Currier D, Haas A, Hendin H. Suicide Prevention Strategies. JAMA. 2005;294(16):2064-74.

5. Yoshimasu K, Kiyohara C, Miyashita K. Suicidal risk factors and completed suicide: meta-analyses based on psychological autopsy studies. Environ Health Prev Med. 2008;13(5):243-56.

6. World Health Organization. Preventing suicide: a global imperative. Geneva: World Health Organization; 2014.

7. Althaus D, Hegerl U. The evaluation of suicide prevention activities: state of the art. World J Biol Psychiatry. 2003;4(4):156-65.

8. Hegerl U, Wittmann M, Arensman E, van Audenhove C, Bouleau JH, van der Feltz-Cornelis C, et al. The "European alliance against depression (EAAD)": a multifaceted, community-based action programme against depression and suicidality. World J Biol Psychiatry. 2008;9(1):51-8.

9. Hegerl U, Wittenburg L, Arensman E, Van Audenhove C, Coyne JC, McDaid $D$, et al. Optimizing suicide prevention programs and their implementation in Europe (OSPI Europe): an evidence-based multi-level approach. BMC Public Health. 2009:9:428

10. Hegerl U, Althaus D, Schmidtke A, Niklewski G. The alliance against depression: 2-year evaluation of a community-based intervention to reduce suicidality. Psychol Med. 2006;36(9):1225-33.

11. Knox KL. Risk of suicide and related adverse outcomes after exposure to a suicide prevention programme in the US air force: cohort study. BMJ. 2003; 327(7428):1376.

12. Ono $Y$, Sakai $A$, Otsuka $K, U d a ~ H, ~ O y a m a ~ H$, Ishizuka $N$, et al. Effectiveness of a multimodal community intervention program to prevent suicide and suicide attempts: a quasi-experimental study. PLoS One. 2013;8(10):e74902.

13. Székely A, Konkolÿ Thege B, Mergl R, Birkás E, Rózsa S, Purebl G, Hegerl U. How to decrease suicide rates in both genders? An effectiveness study of a community-based intervention (EAAD). PLoS One. 2013;8(9):e75081.

14. Van der Feltz-Cornelis CM, Sarchiapone M, Postuvan V, Volker D, Roskar S, Grum AT, et al. Best practice elements of multilevel suicide prevention strategies: a review of systematic reviews. Crisis. 2011;32(6):319-33.

15. Zalsman G, Hawton K, Wasserman D, van Heeringen $K$, Arensman E, Sarchiapone $M$, et al. Suicide prevention strategies revisited: 10-year systematic review. Lancet Psychiatry. 2016;3(7):646-59.

16. Arensman E, Coffey C, Griffin E, Van Audenhove C, Scheerder G, Gusmao R, et al. Effectiveness of depression-suicidal behaviour gatekeeper training among police officers in three European regions: outcomes of the Optimising suicide prevention Programmes and their implementation in Europe (OSPI-Europe) study. Int J Soc Psychiatry. 2016;62(7):651-60.

17. Coppens E, Van Audenhove C, Iddi S, Arensman E, Gottlebe K, Koburger N, et al. Effectiveness of community facilitator training in improving knowledge, attitudes, and confidence in relation to depression and suicidal behavior: results of the OSPI-Europe intervention in four European countries. J Affect Disord. 2014;165:142-50.

18. Slade K, Forrester A. Shifting the paradigm of prison suicide prevention through enhanced multi-agency integration and cultural change. J Forensic PsychiatPsychol. 2015;26(6):737-58.

19. Walrath C, Godoy Garraza L, Reid H, Goldston DB, \& Mckeon R. Impact of the garrett lee smith youth suicide prevention program on suicide mortality. 2015. doi.org/10.2105/AJPH.2014

20. Ayer $L$, Ramchand R, Geyer L, Burgette $L$, Kofner $A$. The influence of training, reluctance, efficacy, and stigma on suicide intervention behavior among NCOs in the Army and marine corps. J Prim Prev. 2016;37(3):287-302.
21. Cross W, Matthieu MM, Lezine $D Q$, Knox KL. Does a brief suicide prevention gatekeeper training program enhance observed skills? Crisis. 2010;31(3):149-59.

22. Marzano L, Smith M, Long M, Kisby C, Hawton K. Police and suicide prevention: evaluation of a training program. Crisis. 2016;37(3):194-204.

23. McLean K, Becker MAS. Bridging the gap: connecting resident assistants and suicidal residents through gatekeeper training. Suicide Life Threat Behav. 2017; https://doi.org/10.1111/sltb.12348.

24. Chauliac N, Brochard N, Payet C, Margue Y, Bordin P, Depraz P, et al. How does gatekeeper training improve suicide prevention for elderly people in nursing homes? A controlled study in 24 centres. European Psychiatry. 2016;37:56-62.

25. Cwik MF, Tingey L, Wilkinson R, Goklish N, Larzelere-Hinton F, Barlow A. Suicide prevention gatekeeper training: can they advance prevention in Indian country? Archives of Suicide Research. 2016;20(3):402-11.

26. Nasir BF, Hides L, Kisely S, Ranmuthugala G, Nicholson GC, Black E, et al. The need for a culturally-tailored gatekeeper training intervention program in preventing suicide among indigenous peoples: a systematic review. BMC Psychiatry. 2016;16(1):357.

27. Silva C, Smith AR, Dodd DR, Covington DW, Joiner TE. Suicide-related knowledge and confidence among behavioral health care staff in seven states. Psychiatr Serv. 2016;67(11):1240-5.

28. Tompkins TL, Witt J, Abraibesh N. Does a gatekeeper suicide prevention program work in a school setting? Evaluating training outcome and moderators of effectiveness. Suicide Life Threat Behav. 2010;40(5):506-15.

29. Wyman PA, Brown CH, Inman J, Cross W, Schmeelk-Cone K, Guo J, Pena JB. Randomized trial of a gatekeeper program for suicide prevention: 1-year impact on secondary school staff. J Consult Clin Psychol. 2008;76(1):104-15.

30. Bean G, Baber KM. Connect: an effective community-based youth suicide prevention program. Suicide Life Threat Behav. 2011;41(1):87-97.

31. Teo AR, Andrea SB, Sakakibara R, Motohara S, Matthieu MM, Fetters MD. Brief gatekeeper training for suicide prevention in an ethnic minority population: a controlled intervention. BMC Psychiatry. 2016;16:211.

32. Hashimoto N, Suzuki Y, Kato TA, Fujisawa D, Sato R, Aoyama-Uehara K, et al. Effectiveness of suicide prevention gatekeeper-training for university administrative staff in Japan. Psychiatry Clin Neurosci. 2016;70(1):62-70.

33. Rodi MS, Garraza LG, Walrath C, Stephens RL, Condron DS, Hicks BB, McKeon R. Referral patterns for youths identified at risk for suicide by trained gatekeepers. Crisis. 2012;33(2):113-9.

34. Susanne Condron D, Garraza LG, Walrath CM, McKeon R, Goldston DB, Heilbron NS. Identifying and referring youths at risk for suicide following participation in school-based gatekeeper training. Suicide Life Threat Behav. 2015;45(4):461-76.

35. Tsai WP, Lin LY, Chang HC, Yu LS, Chou MC. The effects of the gatekeeper suicide-awareness program for nursing personnel. Perspect Psychiatr Care. 2011:47(3):117-25.

36. Mason K, Geist M, Kuo R, Marshall D, Wines JD. Predictors of Clergy's ability to fulfill a suicide prevention gatekeeper role. J Pastoral Care Counsel. 2016; 70(1):34-9.

37. Quinnett, P. QPR gatekeeper training for suicide prevention. The Model, Theory and Research. (C) 2012. http://www.qprinstitute.com/uploads/ QPR\%20Theory\%20Paper.pdf. Accessed 01 Dec 2016.

38. Isaac M, Elias B, Katz LY, Belik SL, Deane FP, Enns MW, et al. Gatekeeper training as a preventative intervention for suicide: a systematic review. Can J Psychiatr. 2009;54(4):260-8.

39. Burnette $C$, Ramchand $R$, Ayer L. Gatekeeper training for suicide prevention. A theoretical model and review of the empirical literature. Rand Health Q. 2015;5(1):16. https://www.ncbi.nlm.nih.gov/pmc/articles/PMC5158249/. Accessed 10 Mar 2017

40. Lipson SK. A comprehensive review of mental health gatekeepertrainings for adolescents and young adults. Int J Adolesc Med Health. 2014;26(3):309-20.

41. Gilissen, R., De Bruin, K., Burger, I., \& Van Hemert, B. Kenmerken van personen overleden door zelfdoding. Epidemiologisch bulletin. 2013;48(4). https://www.113.nl/sites/default/files/113/Artikelen/EPIBUL-2013-Gilissenkenmerken\%20zelfdoding.pdf. Accessed 21 Nov 2016.

42. Steendam M. Gatekeepers in gesprek met suïcidale jongeren. Tijdschrift voor Jeugdgezondheidszorg. 2015;48(4):117.

43. Quinnet P. What is QPR? http://www.qprinstitute.com/about-qpr. Accessed 12 Dec 2016. 
44. De Beurs DP, De Groot MH, De Keijser J, Mokkenstorm J, Van Duijn E, De Winter RFP, Kerkhof AJFM. The effect of an e-learning supported train-the-trainer programme on implementation of suicide guidelines in mental health care. J Affect Disord. 2015;175:446-53.

45. Oordt MS, Jobes DA, Fonseca VP, Schmidt SM. Training mental health professionals to assess and manage suicidal behavior: can provider confidence and practice behaviors be altered? Suicide Life Threat Behav. 2009:39(1):21-32.

46. Bland JM, Altman DG. Multiple significance tests: the Bonferroni method. BMJ. 1995;310:170.

47. Barra M, Simonsen TB, \& Dahl FA. Pre-contact by telephone increases response rates to postal questionnaires in a population of stroke patients: an open ended randomized controlled trial. BMC Health Serv Res. 2016;16(16).

48. Public Health Agency (Northern Ireland) and National Office for Suicide Prevention (NOSP). All island evaluation of applied suicide intervention skills training (ASIST): summary report. Belfast: Northern Ireland and Republic of Ireland: Public Health Agency; 2011. http://www.publichealth.hscni.net/sites/ default/files/ASIST\%20Report\%20FINAL_2.pdf. Accessed 25 Jan 2017.

49. Langendam et al., Alternatieven voor randomized controlled trials in onderzoek naar de effectiviteit van interventies, Dutch Cochrane Centre, 2013. https://www.zonmw.n//fileadmin/documenten/DoelmatigheidsOnderzoek/ Biilage 5. Kennissynthese.pdf. Accessed 06 Dec 2016.

50. Ewell Foster CJ, Burnside AN, Smith PK, Kramer AC, Wills A, A King C. Identification, response, and referral of suicidal youth following applied suicide intervention skills training. Suicide Life Threat Behav. 2017:47(3):297-308.

51. Cross WF, Seaburn D, Gibbs D, Schmeelk-Cone K, White AM, Caine ED. Does practice make perfect? A randomized control trial of behavioral rehearsal on suicide prevention gatekeeper skills. J Prim Prev. 2011;32(3-4):195-211.

52. Lipson SK, Speer N, Brunwasser S, Hahn E, Eisenberg D. Gatekeeper training and access to mental health care at universities and colleges. J Adolesc Health. 2014;55(5):612-9.

53. Cross W, Matthieu MM, Cerel J, Knox KL. Proximate outcomes of gatekeeper training for suicide prevention in the workplace. Suicide Life Threat Behav. 2007;37(6):659-70.

\section{Ready to submit your research? Choose BMC and benefit from}

- fast, convenient online submission

- thorough peer review by experienced researchers in your field

- rapid publication on acceptance

- support for research data, including large and complex data types

- gold Open Access which fosters wider collaboration and increased citations - maximum visibility for your research: over $100 \mathrm{M}$ website views per year

At BMC, research is always in progress.

Learn more biomedcentral.com/submissions 